\title{
Interaction of the Hypothalamic Paraventricular Nucleus and Central Nucleus of the Amygdala in Naloxone Blockade of Neuropeptide Y-Induced Feeding Revealed by c-fos Expression
}

\author{
James D. Pomonis, ${ }^{1}$ Allen S. Levine, ${ }^{1,2,3,4}$ and Charles J. Billington ${ }^{2,3,4}$ \\ ${ }^{1}$ Graduate Program in Neuroscience and ${ }^{2}$ Department of Medicine, University of Minnesota, Minneapolis, Minnesota \\ 55455, 3Minnesota Obesity Center, Minneapolis, Minnesota 55417, and ${ }^{4}$ Veterans Affairs Medical Center, Minneapolis, \\ Minnesota 55417
}

\begin{abstract}
Neuropeptide Y (NPY) is a powerful inducer of food intake with a key site of action in the paraventricular nucleus (PVN) of the hypothalamus. An effective method for inhibiting the effects of NPY is pretreatment with the opioid antagonists naloxone or naltrexone. In the present study, we used immunohistochemistry for cFos as a marker of neuronal activity to map the effects of PVN-injected NPY and blockade of these effects by peripheral injection of naloxone. Injection of NPY into the PVN resulted in an increase in food intake that was blocked by peripheral administration of naloxone. PVN NPY also resulted in increased cFos immunoreactivity (cFos-IR) in the PVN independent of food intake, and although peripheral naloxone inhibited NPY-induced feeding, it did not alter cFos-IR in the PVN. cFos-IR in the central nucleus of the amygdala (CNA) increased
\end{abstract}

in response to both NPY and naloxone. Furthermore, the response to NPY and naloxone was additive, suggesting that peripheral naloxone and PVN NPY activate different neuronal populations in the CNA. Three other brain regions, the nucleus of the solitary tract, the ventrolateral medulla, and the supraoptic nucleus, all showed increases in cFos-IR in this study, but these changes came only as a result of increased food intake after PVN-injected NPY. The current data suggest that the CNA is a site important for the integration of the NPY and opioid systems.

Key words: neuropeptide Y; feeding; opioids; paraventricular nucleus; central nucleus of the amygdala; nucleus of the solitary tract
Neuropeptide Y (NPY) is a member of the pancreatic polypeptide family and is the most potent stimulator of feeding known. NPY is also known to affect energy balance, suggesting that it plays a crucial role in a central neural network involved in energy homeostasis. Central administration of NPY results in increased feeding (Clark et al., 1984; Levine and Morley, 1984; Stanley and Leibowitz, 1984), decreased firing of sympathetic fibers innervating brown adipose tissue (BAT) (Egawa et al., 1991), decreased BAT activity as measured by uncoupling protein (UCP) mRNA levels, and increased fat storage in white adipose tissue (Billington et al., 1991, 1994). It has been determined that the primary site of action of NPY in the regulation of these effects is in the hypothalamus, particularly the paraventricular nucleus (PVN) (Stanley et al., 1985; Abe, 1989; Billington et al., 1994) or the nearby perifornical area (Stanley et al., 1993). NPY immunoreactivity is highest in the PVN, almost exclusively in nerve terminals (Allen et al., 1983; Chronwall et al., 1985; Sawchenko et al., 1985; Stanley et al., 1993), a large portion of which arise from cell bodies in the arcuate nucleus (ARC) (Morris, 1989).

This ARC-PVN NPYergic pathway has been shown to be highly sensitive to energy status. ARC NPY mRNA and PVN NPY levels increase in response to food deprivation or food

Received Feb. 19, 1997; revised April 8, 1997; accepted April 11, 1997.

This work was supported by National Institutes of Health Diabetes and Digestive and Kidney Diseases Grant 42698 and by the Department of Veterans Affairs. We thank Joe Ghilardi and Dr. Patrick Mantyh for their technical assistance with this manuscript.

Correspondence should be addressed to Dr. Charles J. Billington, Research Service (151), Veterans Affairs Medical Center, One Veterans Drive, Minneapolis, MN 55417.

Copyright (C) 1997 Society for Neuroscience $\quad 0270-6474 / 97 / 175175-08 \$ 05.00 / 0$ restriction and normalize after refeeding (Sahu et al., 1988; Calza et al., 1989; Brady et al., 1990; Pages et al., 1993). It has also been shown that NPY release in the PVN increases before a scheduled meal and decreases after the meal (Kalra et al., 1991).

It has been documented that blockade of opioid receptors inhibits both the orexigenic (Levine et al., 1990a,b; Lambert et al., 1993; Shibasaki et al., 1995) and thermogenic effects of NPY (Kotz et al., 1995). Peripheral or intracerebroventricular injection of naloxone, naltrexone, or specific opioid antagonists before central administration of NPY blocks the increase in food intake and the decrease in UCP mRNA in BAT seen with NPY injection alone. The site of action of naloxone is different from that of NPY, however, because naltrexone injection into the PVN is ineffective at inhibiting either the orexigenic or thermogenic effects of PVNadministered NPY (Kotz et al., 1995). This suggests that there is an interaction between NPY and opioid systems in regard to the role of NPY in energy homeostasis, with the two systems having separate primary sites of action.

Microinjection studies have shed further light on this interaction between NPY and opioids. Injection of naltrexone into the rostral nucleus of the solitary tract (rNTS) before PVN injection of NPY abolished the feeding and thermogenic effects seen with PVN NPY injections alone (Kotz et al., 1995). Thus, the NTS was implicated along with the ARC and PVN in the circuitry mediating the effects of NPY on energy balance; however, it was unclear whether the inhibitory effects of naloxone on NPY were mediated by NTS to PVN efferents or by PVN to NTS efferents. The purpose of this study was to examine cFos immunoreactivity (cFos-IR) to determine possible brain nuclei involved in the interaction of NPY and naloxone. 


\begin{tabular}{llll}
\hline Table 1. Key to treatment groups & & \\
Treatment & Peripheral injection & PVN injection & Food available? \\
\hline sal/sal & Saline $(0.9 \%)$ & Saline $(0.9 \%)$ & Yes \\
nlx/sal & Naloxone $(1 \mathrm{mg} / \mathrm{kg})$ & Saline $(0.9 \%)$ & Yes \\
sal/NPY & Saline $(0.9 \%)$ & NPY $(1 \mu \mathrm{g})$ & Yes \\
sal/NPY(D) & Saline $(0.9 \%)$ & NPY $(1 \mu \mathrm{g})$ & No \\
nlx/NPY & Naloxone $(1 \mathrm{mg} / \mathrm{kg})$ & NPY $(1 \mu \mathrm{g})$ & Yes \\
\hline
\end{tabular}

\section{MATERIALS AND METHODS}

Experimental procedures. Forty-one male Sprague Dawley rats (Harlan, Madison, WI) weighing 250-325 gm at the start of the experiment were used in this study. They were housed individually in wire mesh cages on a $12 \mathrm{hr}$ light/dark cycle (lights on at 7 A.M.). Rats had ad libitum access to food and water at all times except where noted. Under Nembutal anesthesia, rats had stainless steel guide cannulas (Plastics One, Roanoke, VA) implanted into the right PVN using the following coordinates from bregma according to the atlas of Paxinos and Watson (1986): $0.5 \mathrm{~mm}$ lateral, $1.9 \mathrm{~mm}$ posterior, and $7.3 \mathrm{~mm}$ below the surface of the skull. Rats were allowed 1 week to recover from surgery before experimental manipulations were begun. On experimental days, rats received an intraperitoneal injection of either $1 \mathrm{mg} / \mathrm{kg}$ naloxone (RBI, Natick, MA) or isotonic saline followed 30 min later by a PVN injection of $1 \mu \mathrm{g} / \mu \mathrm{l}$ NPY (Peninsula Inc., Belmont, CA) or $1 \mu \mathrm{l}$ isotonic saline; they were killed 1 hr later.

Five treatment groups of seven to nine rats per group were used in this study (Table 1). The first group (sal/sal) received an intraperitoneal injection of $0.9 \%$ saline followed by a PVN injection of $0.9 \%$ saline. The second group (nlx/sal) received an intraperitoneal injection of $1 \mathrm{mg} / \mathrm{kg}$ naloxone followed by a PVN injection of $0.9 \%$ saline. The third group (sal/NPY) received an intraperitoneal injection of $0.9 \%$ saline and a PVN injection of $1 \mu \mathrm{g}$ NPY. The fourth group [sal/NPY(D)] received an intraperitoneal injection of $0.9 \%$ saline and a PVN injection of $1 \mu \mathrm{g}$ NPY but was deprived of food after injections. This group was included to control for possible effects that food consumption may have on cFos-IR. The fifth group (nlx/NPY) received an intraperitoneal injection of 1 $\mathrm{mg} / \mathrm{kg}$ naloxone followed by a PVN injection of $1 \mu \mathrm{g}$ NPY. The group abbreviations in parentheses will be used throughout the remainder of this paper.

Tissue preparation and immunohistochemical methods. One hour after the PVN injection, animals were asphyxiated by $\mathrm{CO}_{2}$ and perfused rapidly through the aorta with $180 \mathrm{ml}$ of cold $\mathrm{Ca}^{2+}$-free Tyrode's solution, followed by slow perfusions with $400 \mathrm{ml}$ of Lana's fix and then $400 \mathrm{ml}$ of $10 \%$ sucrose in Sorenson's buffer. Brains then were removed and stored in $10 \%$ sucrose/Sorenson's at $4^{\circ} \mathrm{C}$ for a minimum of $24 \mathrm{hr}$ until they were sectioned. Frozen sections were cut on a cryostat at a thickness of $40 \mu \mathrm{m}$ and immediately cryoprotected in sucrose/ethylene glycol and stored at $-20^{\circ} \mathrm{C}$ until ready for use in immunohistochemistry. Storage of tissue in this manner preserves antigenicity and morphology for up to $90 \mathrm{~d}$ (Watson et al., 1986).

For cFos immunohistochemistry, sections containing the anatomical areas of interest were removed from the cryoprotectant solution and rinsed $4 \times 5 \mathrm{~min}$ in PBS followed by a 30 min incubation in blocking solution ( $2 \%$ normal goat serum $/ 0.1 \%$ BSA $/ 0.2 \%$ Triton X-100 in PBS). Sections were then rinsed $3 \times 5 \mathrm{~min}$ in PBS and incubated for $48 \mathrm{hr}$ at $4^{\circ} \mathrm{C}$ in cFos antiserum (Oncogene Science, Cambridge, MA) at a dilution of $1: 40,000$. Next, sections were rinsed $8 \times 5 \mathrm{~min}$ in PBS and then incubated in biotinylated goat anti-rabbit IgG (Vector Laboratories, Burlingame, CA) at a dilution of 1:500 for $1 \mathrm{hr}$ at room temperature. Sections were again rinsed $4 \times 5 \mathrm{~min}$ in PBS and then incubated in Vectastain Elite $\mathrm{ABC}$ reagent (Vector Laboratories) for $1 \mathrm{hr}$ at room temperature. Sections were then rinsed $2 \times 5 \mathrm{~min}$ in PBS and $3 \times 5 \mathrm{~min}$ in sodium acetate buffer, followed by incubation with $\mathrm{DAB}-$ nickel sulfate solution for $2.5 \mathrm{~min}$; the reaction was stopped by rinsing $3 \times 5 \mathrm{~min}$ with distilled water. Stained sections were mounted on gelatin-coated slides, air-dried, and coverslipped.

Quantitation of cFos-IR. Sections were viewed using a Leitz Orthoplan 2 microscope, and images were captured using a cooled CCD camera (Optronics Engineering, Goleta, CA) linked to a Power Macintosh 8500/ 120 computer. Captured images were analyzed using National Institutes of Health Image 1.51 software (National Institutes of Health, Bethesda, $\overline{\text { Table 2. Rostral and caudal extents of brain sites examined for cFos-IR }}$

\begin{tabular}{lcc} 
Site & Rostral extent & Caudal extent \\
\hline PVN & $-1.40 \mathrm{~mm}$ & $-2.12 \mathrm{~mm}$ \\
CNA & $-2.30 \mathrm{~mm}$ & $-3.14 \mathrm{~mm}$ \\
iNTS & $-13.30 \mathrm{~mm}$ & $-14.08 \mathrm{~mm}$ \\
rNTS & $-11.80 \mathrm{~mm}$ & $-13.30 \mathrm{~mm}$ \\
VLM & $-13.30 \mathrm{~mm}$ & $-14.08 \mathrm{~mm}$ \\
SON & $-1.30 \mathrm{~mm}$ & $-1.80 \mathrm{~mm}$ \\
\hline
\end{tabular}

$\mathrm{MD})$. A region of constant size $\left(\mathrm{mm}^{2}\right)$ that completely contained the anatomical area of interest was outlined, and the number of cFos-IR nuclei were counted and expressed as number of cFos-IR nuclei per region of interest. Expression of data for the PVN was slightly different because cannula placement often resulted in distortion of the PVN. Because of this, we were frequently unable to obtain constant area measurements of the PVN. Thus, the region corresponding to the PVN was outlined and measured, and the number of cFos-IR cells in that area was counted and expressed as number of cFos-IR cells per $\mathrm{mm}^{2}$. For all sites studied, bilateral measurements were taken on up to three slices per animal. Table 2 shows the coordinates of all sites examined according to the atlas of Paxinos and Watson (1986). Counts were averaged for each animal, and data were analyzed using a one-way repeated measures ANOVA with treatment as the independent variable. Post hoc analysis was performed using Fisher's PLSD test. Seven animals showed improper cannula placement, and data from these animals were discarded. Data from two additional animals were not used in this study, because they were determined to be statistical outliers according to the universal test for the rejection of a single normal outlier (Hawkins, 1980). This test calculates a new $F$ statistic using residual sums of squares, followed by a Bonferonni correction to determine whether a single data point can be considered an outlier.

\section{RESULTS}

Analysis of total food consumed over the $1.5 \mathrm{hr}$ after the initial (peripheral) injection showed a main effect of treatment $\left(F_{(3,30)}=\right.$ $3.69 ; p=0.0226)$. For this analysis, the sal/NPY(D) group was removed, because that group did not have access to food during this time period. Mean food intake ( \pm SEM) was as follows: $\mathrm{sal} / \mathrm{sal}=0.171 \pm 0.171 \mathrm{gm}, \mathrm{nlx} / \mathrm{sal}=0.150 \pm 0.150 \mathrm{gm}, \mathrm{nlx} /$ $\mathrm{NPY}=0.645 \pm 0.225 \mathrm{gm}, \mathrm{sal} / \mathrm{NPY}=1.375 \pm 0.480 \mathrm{gm}$. Post hoc analysis showed that the sal/NPY group ate significantly more food than all other groups and that the sal/sal, nlx/sal, and nlx/NPY groups were not statistically different from one another, demonstrating that peripheral administration of $1 \mathrm{mg} / \mathrm{kg}$ naloxone inhibits the behavioral effects of $1 \mu \mathrm{g}$ of PVN-injected NPY.

In the PVN, there was a main effect of treatment on cFos-IR $\left(F_{(4,29)}=9.361 ; p=0.0001\right)$, with significantly higher levels of cFos-IR in all treatments receiving PVN injections of NPY; however, neither peripheral naloxone nor the presence or absence of food altered cFos-IR in the PVN (Fig. 1). No differences in cFos-IR between the injected and noninjected PVN were seen after NPY administration for any treatments, indicating that unilateral injection of NPY resulted in bilateral activation of the PVN (data not shown).

In the central nucleus of the amygdala (CNA), cFos-IR was affected by both naloxone and NPY injection (Fig. 2). There was a main effect of treatment on cFos-IR in the CNA $\left(F_{(4,23)}=7.493\right.$; $p=0.0005)$, and post hoc analysis showed significant differences between several groups. The nlx/sal, sal/NPY(D), and nlx/NPY groups all showed significantly higher levels of cFos-IR than the sal/sal group. This suggests that peripheral naloxone administration as well as PVN NPY injection independently resulted in a significant increase of cFos-IR in the CNA. When all groups were included in the analysis, NPY failed to significantly increase 

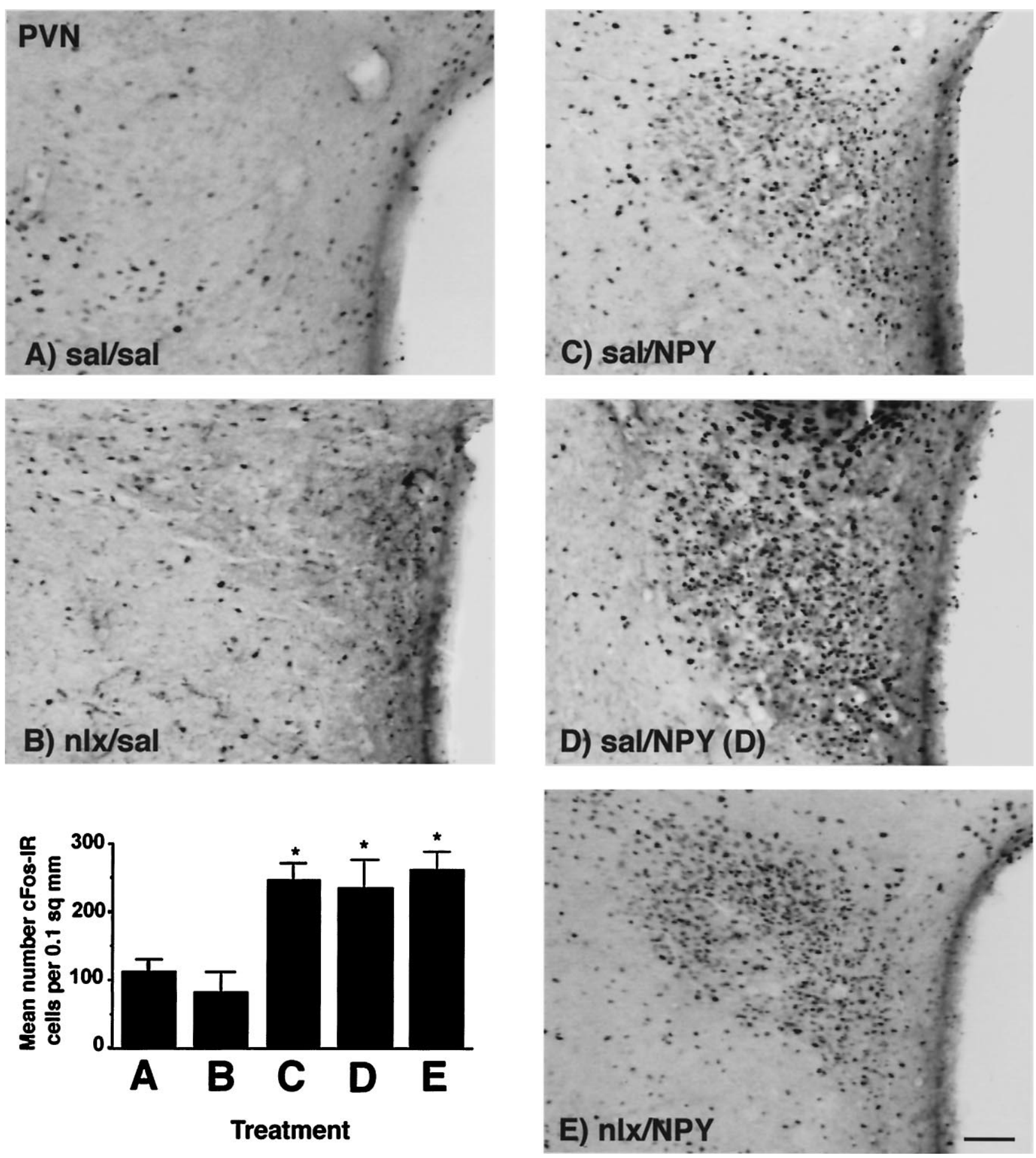

Figure 1. Photomicrographs showing cFos-IR in the PVN in response to peripheral injection of either $0.9 \%$ saline or $1 \mathrm{mg} / \mathrm{kg}$ naloxone, followed 30 min later by PVN injection of either $0.9 \%$ saline or $1 \mu \mathrm{g}$ NPY. cFos-IR was significantly increased by PVN injection of NPY and was not affected by feeding or by blockade of NPY-induced feeding attributable to naloxone injection. Treatments abbreviated as per Table 1 . $A-E$ on photomicrographs correspond to $A-E$ on graph. Graph represents treatment means; error bars represent SEM. *Significant from sal/sal group. Magnification, $25 \times$. Scale bar, $200 \mu \mathrm{m}$.

cFos-IR when food was available. That is, the sal/NPY group was not significantly different from the sal/sal group; however, when a one-way ANOVA was conducted to determine a possible effect of NPY on cFos-IR by using only the sal/sal, sal/NPY(D), and sal/NPY groups, there was a main effect of treatment $\left(F_{(2,11)}=\right.$ 12.926; $p=0.0013)$, with both the sal/NPY(D) and the sal/NPY groups showing significantly higher cFos-IR in the CNA than the sal/sal group according to Fisher's PLSD test. The nlx/NPY group showed the highest levels of cFos-IR of any of the five groups. cFos-IR was significantly higher in the nlx/NPY group than in the sal/sal, nlx/sal, or sal/NPY groups, but was not significantly higher than the sal/NPY(D) group. The patterns of 

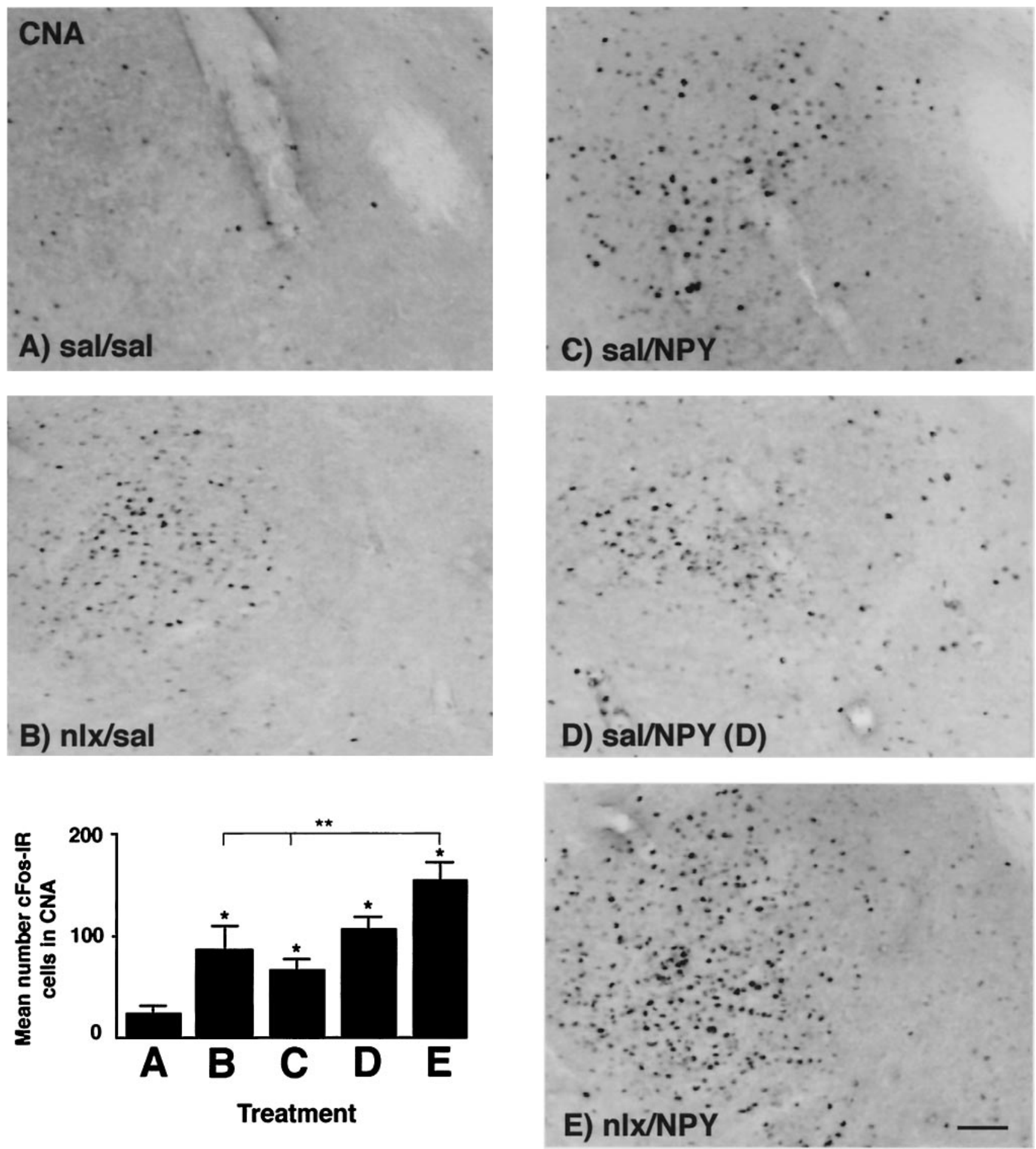

Figure 2. Photomicrographs showing cFos-IR in the CNA in response to peripheral injection of either $0.9 \%$ saline or $1 \mathrm{mg} / \mathrm{kg}$ naloxone, followed 30 min later by PVN injection of either $0.9 \%$ saline or $1 \mu \mathrm{g}$ NPY. cFos-IR was significantly increased by PVN injection of NPY and by peripheral naloxone injection. Treatments abbreviated as per Table 1. $A-E$ on photomicrographs correspond to $A-E$ on graph. Graph represents treatment means; error bars represent SEM. *Significant from sal/sal group; **significant differences among $n l x / N P Y$ group and other groups indicated by line. Magnification, $25 \times$. Scale bar, $200 \mu \mathrm{m}$.

cFos-IR induced by naloxone or NPY did not show specificity to either the medial or lateral subdivisions of the CNA (data not shown).

Figure 3 shows the $c$-fos response in two regions of the NTS: the intermediate NTS (iNTS) and the rNTS. The overall response was the same for both of these regions. In the iNTS, although there was a main effect of treatment $\left(F_{(4,22)}=3.963 ; p=0.0143\right)$, cFos-IR was affected only by the combination of NPY administration and feeding. In the rNTS, again there was a main effect of treatment $\left(F_{(4,22)}=3.032 ; p=0.0392\right)$, with only the sal/NPY group, but not the sal/NPY(D) group, showing significantly higher levels of cFos-IR. 

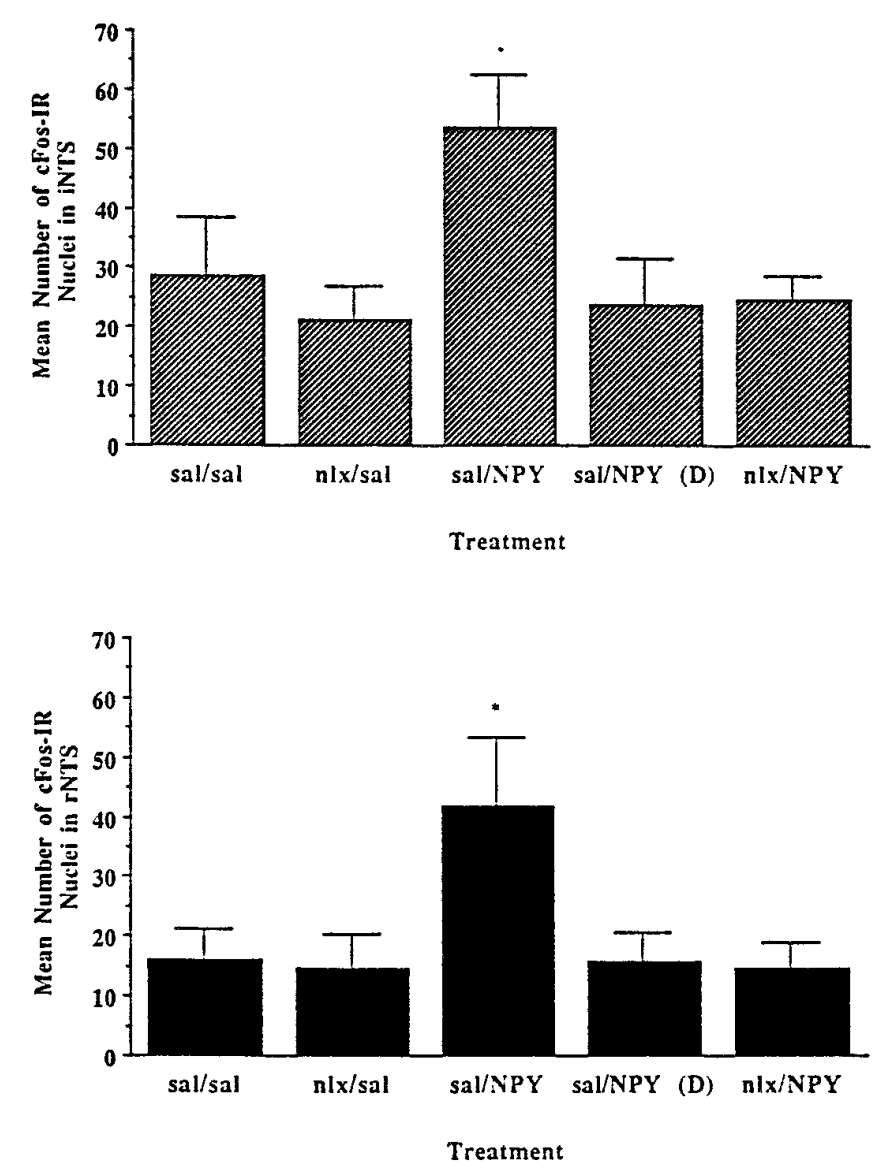

Figure 3. Quantitation of cFos-IR in the rostral nucleus of the solitary tract $(r N T S)$ and the intermediate NTS (iNTS) in response to peripheral injection of either $0.9 \%$ saline or $1 \mathrm{mg} / \mathrm{kg}$ naloxone, followed $30 \mathrm{~min}$ later by PVN injection of either isotonic saline or $1 \mu \mathrm{g}$ NPY. Changes in cFos-IR were seen only in the condition of PVN-administered NPY with food consumption. *Significant from sal/sal control. Error bars represent SEM.

For measurement of cFos-IR in the nearby ventrolateral medulla (VLM), a similar result was seen (Fig. 4). There was a main effect of treatment $\left(F_{(4,22)}=3.495 ; p=0.0236\right)$, with the sal/NPY group being the only group to show a significant increase in cFos-IR. Although the other groups were not statistically affected, there was a trend of increased cFos-IR in response to NPY that was lessened by peripheral administration of naloxone.

In the supraoptic nucleus (SON), cFos-IR was responsive to a combination of NPY and food intake (Fig. 5). There was a main effect of treatment $\left(F_{(4,26)}=4.712 ; p=0.0054\right)$, and post hoc analysis showed that cFos-IR was significantly higher in the sal/ NPY and nlx/NPY groups. This suggests that the cFos-IR in the SON is responsive to NPY and to feeding; however, although cFos-IR in the SON was still significantly higher in the nlx/NPY group than in the sal/sal group, it should be noted that the nlx/NPY group did eat more food (but not significantly more food) than the sal/sal group. When we examined cFos-IR in the SON for an effect of NPY by recalculating the ANOVA using only the sal/sal, sal/NPY(D), and sal/NPY groups, there was a main effect of treatment $\left(F_{(2,16)}=12.011, p=0.0007\right)$. Post hoc analysis showed a statistical increase in cFos-IR only in the sal/NPY group. This suggests that the SON is responsive primarily to feeding and not simply to NPY.

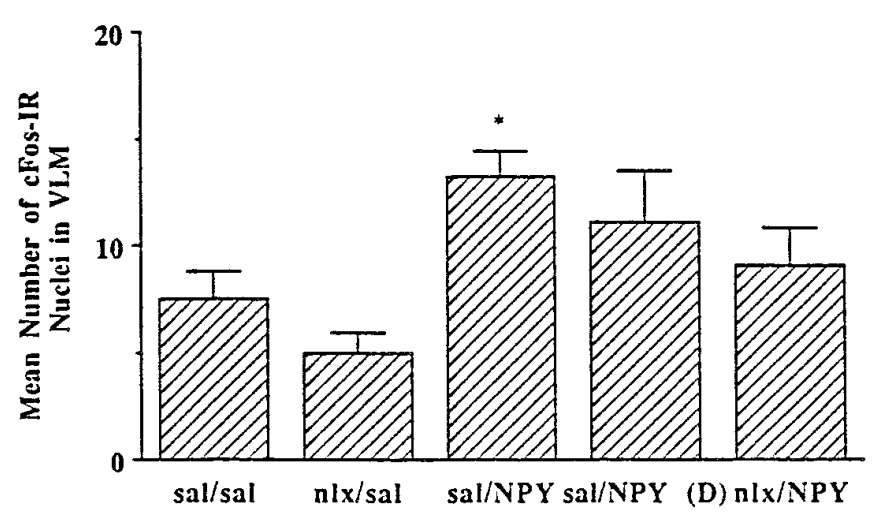

Treatment

Figure 4. Quantitation of cFos-IR in the VLM in response to peripheral injection of either $0.9 \%$ saline or $1 \mathrm{mg} / \mathrm{kg}$ naloxone, followed $30 \mathrm{~min}$ later by PVN injection of either $0.9 \%$ saline or $1 \mu \mathrm{g}$ NPY. Increases in cFos-IR were seen only with PVN NPY injection with food consumption. *Significant from sal/sal control. Error bars represent SEM.

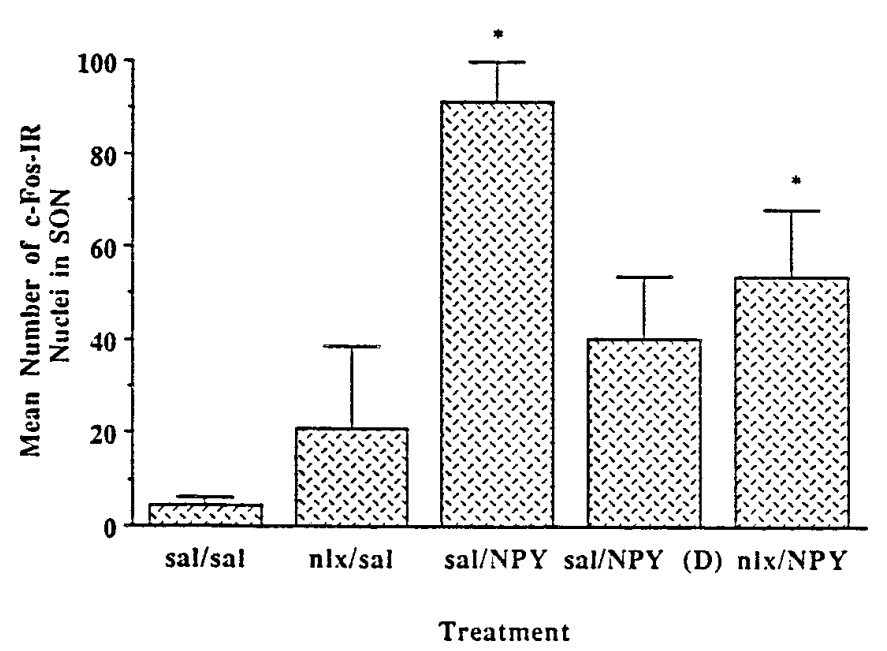

Figure 5. Quantitation of cFos-IR in the SON in response to peripheral injection of either $0.9 \%$ saline or $1 \mathrm{mg} / \mathrm{kg}$ naloxone, followed $30 \mathrm{~min}$ later by PVN injection of either $0.9 \%$ saline or $1 \mu \mathrm{g}$ NPY. Both the $s a l / N P Y$ and $n l x / N P Y$ groups showed significant increases in cFos-IR. * Significant from $\mathrm{sal} / \mathrm{sal}$ control. Error bars represent SEM.

\section{DISCUSSION}

The aim of this study was to determine a possible site or sites within the CNS responsible for the interaction of NPY and naloxone. To accomplish this, we chose to stimulate the PVN directly by microinjection of NPY. This allows for precise activation of the PVN, a region known to be involved in the control of food intake and energy balance (Billington et al., 1994). We chose to examine cFos-IR, because this technique has been shown to be useful in metabolic mapping studies in both mono- and multisynaptic systems (Sagar et al., 1988). Because naloxone failed to alter NPYinduced cFos-IR in the PVN, we conclude that naloxone inhibits the effects of NPY at a site outside the PVN.

The data presented here suggest that NPY induces feeding by activation of neurons within the PVN that in turn project to other, possibly extrahypothalamic sites where there is an interaction with an opioidergic system. The PVN was solely responsive to the presence or absence of NPY and was unaffected by naloxone or the increased food intake induced by NPY administration. Al- 
though naloxone had a robust antagonistic effect on the behavioral effects of NPY, naloxone does not seem to antagonize the effects of PVN-injected NPY at the level of the PVN, because NPY-induced cFos-IR in the PVN was unaffected by naloxone. Furthermore, naloxone did not affect basal levels of cFos-IR in the PVN.

These results confirm previous findings that the PVN is a principal site of action of NPY. Increases in cFos-IR in the PVN after central administration of NPY have been reported previously (Li et al., 1994; Lambert et al., 1995; Xu et al., 1995), with slightly varying results. Li et al. (1994) and Xu et al. (1995) both reported that cFos-IR in the PVN increased after ventricular injection of NPY and increased even further when rats were allowed to eat after NPY administration. In the current study, we did not see any effects of food intake on cFos-IR in the PVN, nor did Lambert et al. (1995), who examined cFos-IR in various subregions of the PVN after intracerebroventricular injection of NPY. The data from this study also support previous work that has shown that the PVN is not the site of the antagonistic effects of naloxone on NPY (Kotz et al., 1995).

The data from the CNA are perhaps the most compelling in this study. The extended amygdala, and especially the CNA, have been reported to play both stimulatory and inhibitory roles in the control of food intake. Kainic acid lesions of the CNA have been reported to increase feeding and body weight (Hajnal et al., 1992), as have electrolytic lesions of the posterodorsal amygdala (King et al., 1993, 1994, 1997). Chemical stimulation of the CNA with the $\mathrm{GABA}_{\mathrm{A}}$ antagonist bicuculline (Minano et al., 1992) or various opioid agonists also results in increased food intake (for review, see Gosnell and Levine, 1996). Conversely, CNA injections of the $\mathrm{GABA}_{\mathrm{A}}$ agonist muscimol decrease deprivation-induced feeding (Minano et al., 1992), as do injections with a number of opioid antagonists (for review, see Bodnar, 1996). In the current study we report evidence for two distinct neuronal populations within the CNA that may play separate roles in the interaction of the hypothalamic NPYergic system with an opioidergic system. Our data show increased cFos-IR in the CNA after peripheral naloxone administration and increases in cFos-IR in the CNA after PVN injection of NPY. Furthermore, when naloxone and NPY are coadministered, the cFos-IR in the CNA is elevated not only from the baseline controls but from the groups receiving either naloxone or NPY alone. Similar to results seen in the PVN, cFos-IR in the CNA was unresponsive to increased feeding after NPY, contrary to results reported previously (Li et al., 1994).

Although there was not regional specificity in $c$-fos expression after administration of NPY or naloxone, the additive effect seen after coadministration suggests that two distinct neuronal populations are activated: one by NPY and the other by naloxone. The fact that the pattern of cFos-IR in the CNA in response to naloxone and NPY does not mimic the behavioral effects seen when these two substances are coadministered suggests that the CNA may integrate rather than regulate the inhibitory effects of naloxone on NPY; i.e., a site that receives projections from the CNA may be responsive to NPY, and naloxone-activated cells in the CNA may inhibit the NPY-induced activation of that area. Of the five sites we examined, none showed a pattern of cFos-IR consistent with this scenario, but other areas (such as the parabrachial nucleus, the nucleus accumbens, and the lateral septum) may be candidates for such a site. Although it has been demonstrated that the CNA projects directly to the PVN (Gray et al., 1989), reciprocal projections have not been identified. Our data demonstrate a PVN-CNA pathway, but whether this is a mono- or multisynaptic pathway cannot be determined here.

Along with various forebrain regions, several hindbrain areas, including the NTS, have been implicated in the regulation of food intake. Given that naltrexone administration into the NTS inhibits the increased feeding and decreased thermogenesis seen after PVN-injected NPY (Kotz et al., 1995), we originally hypothesized that we would see increased cFos-IR in the NTS in response to NPY, which in turn would be inhibited by naloxone; however, we saw increases in cFos-IR only in response to NPY and food intake but not to NPY alone. The pattern of $c$-fos expression was nearly identical for the two subregions of the NTS examined. Similar increases in cFos-IR in the NTS have been seen after food intake (Fraser and Davison, 1993; Fraser et al., 1995) or infusion of nutrients directly into the digestive system (Zittel et al., 1994).

One possible explanation for the failure of either naloxone or NPY alone to affect cFos-IR in the NTS is that naloxone or NPY could indeed activate cells in the NTS, but after activation these cells do not show increased levels of $c$-fos expression. Another explanation could be that naloxone blocks opioid receptors located on fibers in the NTS, but the affected cell bodies may lie in other, distal regions. If this latter circumstance were the case, no changes in cFos-IR in the NTS would be seen, because cFos is a nuclear protein. Neuroanatomical evidence supports interactions between the NTS and both the PVN and CNA. There are projections from the NTS to the CNA (Petrov et al., 1993; ZardettoSmith and Gray, 1996) and projections from the CNA to the NTS (Petrov et al., 1995; Pickel et al., 1995). It may be that peripheral naloxone administration blocks opioid receptors in the NTS, the result of which is seen as alterations in $c$-fos expression in neurons located in the CNA. Finally, it may be that naloxone can act at more than one site to inhibit the effects of NPY, and peripheral injection of naloxone acts primarily at the CNA and not the NTS.

The VLM is another area studied that may play an important role in mediating the effects of the hypothalamic NPYergic system. Although our data show increased cFos-IR in the VLM only after NPY-induced feeding and not with NPY administration alone, there is a trend of increased cFos-IR after PVN injection of NPY without food intake [sal/NPY(D) group]. Peripheral naloxone injection before PVN NPY administration abolished this trend. The VLM may be a candidate for the effects of NPY on sympathetic nervous system activity. The VLM has been implicated in various autonomic functions such as blood pressure and heart rate (Granata et al., 1986), and projections from the PVN have been demonstrated to course through the VLM to various adipose tissue stores (Warren et al., 1996). Furthermore, the VLM is connected with several of the structures mentioned previously. The VLM innervates the amygdala (Palkovits et al., 1992; Petrov et al., 1993; Roder and Ciriello, 1993; Ciriello et al., 1994), the PVN (Palkovits et al., 1992; Petrov et al., 1993; Rinaman et al., 1995), and the NTS (Sawchenko and Swanson, 1981).

Evidence exists that the SON is responsive to alterations in feeding (Verbalis et al., 1986; Li et al., 1994; Xu et al., 1995), although it has not been shown to play stimulatory or inhibitory roles in food intake regulation. The increases in cFos-IR in the SON seen here are in agreement with those seen previously in which the SON seems to be mostly responsive to feeding (Li et al., 1994; Xu et al., 1995). This likely reflects a release of oxytocin in response to food intake, as has been reported previously (Verbalis et al., 1986). In this study we did not see an increase in cFos-IR in response to NPY alone, as seen previously (Li et al., 1994; Xu et al., 1995). This may be attributable to differences in sites of 
injection. In these previous studies, injections of NPY were made into either the lateral ventricle ( $\mathrm{Li}$ et al., 1994) or the fourth ventricle (Xu et al., 1995), whereas we injected NPY directly into the PVN. Although there are no direct connections from the PVN to the SON (Cirino and Renaud, 1985), the SON is innervated by the CNA, which could explain the modest albeit not significant increase in cFos-IR in the SON in response to PVN NPY in the absence of food intake.

In summary, we have seen that NPY-induced cFos-IR in the PVN is not affected by either feeding or peripheral naloxone injection, but neurons within the CNA are activated by both naloxone and NPY. The neurons in the CNA that are activated by naloxone may have a different neurochemical profile than those activated by PVN NPY, because the $c$-fos response in the CNA is additive. These data suggest that the amygdala, specifically the CNA, may be a critical structure in the interaction of the NPYergic and opioidergic systems in food intake regulation.

\section{REFERENCES}

Abe M, Saito M, Shimazu T (1989) Neuropeptide Y and norepinephrine injected into the paraventricular nucleus of the hypothalamus activate endocrine pancreas. Biomed Res 10:431-436.

Allen YS, Adrian TE, Allen JM, Tatemoto K, Crow TJ, Bloom SR, Polak JM (1983) Neuropeptide Y distribution in the rat brain. Science 221:877-879.

Billington CJ, Briggs JE, Grace M, Levine AS (1991) Effects of intracerebroventricular injection of neuropeptide $\mathrm{Y}$ on energy metabolism. Am J Physiol 260:R321-R327.

Billington CJ, Briggs JE, Harker S, Grace M, Levine AS (1994) Neuropeptide $\mathrm{Y}$ in hypothalamic paraventricular nucleus: a center coordinating energy metabolism. Am J Physiol 266:R1765-R1770.

Bodnar RJ (1996) Opioid receptor subtype antagonists and ingestion. In: Drug receptor subtypes and ingestive behaviour (Cooper SJ, Clifton PG, eds), pp. 127-146. San Diego: Academic.

Brady LS, Smith MA, Gold PW, Herkenham M (1990) Altered expression of hypothalamic neuropeptide mRNAs in food-restricted and fooddeprived rats. Neuroendocrinology 52:441-447.

Calza L, Giardino L, Battistini N, Zanni M, Galletti S, Protopapa F, Velardo A (1989) Increase of neuropeptide Y-like immunoreactivity in the paraventricular nucleus of fasting rats. Neurosci Lett 104:99-104.

Chronwall BM, DiMaggio DA, Massari VJ, Pickel VM, Ruggiero DA, O'Donohue TL (1985) The anatomy of neuropeptide-Y-containing neurons in rat brain. Neuroscience 15:1159-1181.

Ciriello J, Schultz CG, Roder S (1994) Collateral axonal projections from ventrolateral medullary non-catecholaminergic neurons to central nucleus of the amygdala. Brain Res 663:346-351.

Cirino M, Renaud LP (1985) Influence of lateral septum and amygdala stimulation on the excitability of hypothalamic supraoptic neurons: an electrophysiological study in the rat. Brain Res 326:357-361.

Clark JT, Kalra PS, Crowley WR, Kalra SP (1984) Neuropeptide Y and human pancreatic polypeptide stimulate feeding behavior in rats. Endocrinology 115:427-429.

Egawa M, Yoshimatsu H, Bray GA (1991) Neuropeptide Y suppresses sympathetic activity to interscapular brown adipose tissue in rats. Am J Physiol 260:R328-R334.

Fraser KA, Davison JS (1993) Meal-induced c-fos expression in brain stem is not dependent on cholecystokinin release. Am J Physiol 265:R235-R239.

Fraser KA, Raizada E, Davison JS (1995) Oral-pharyngeal-esophageal and gastric cues contribute to meal-induced $c$-fos expression. Am J Physiol 268:R223-R230.

Gosnell BA, Levine AS (1996) Stimulation of ingestive behaviour by preferential and selective opioid agonists. In: Drug receptor subtypes and ingestive behaviour. (Cooper SJ, Clifton PG, eds), pp. 147-166. San Diego: Academic.

Granata AR, Numao Y, Kumada M, Reis D (1986) A1 noradrenergic neurons tonically inhibit sympathoexcitatory neurons of $\mathrm{C} 1$ area in rat brainstem. Brain Res 377:127-146.

Gray T, Carney M, Magnuson D (1989) Direct projections from the central amygdaloid nucleus to the hypothalamic paraventricular nu- cleus: possible role in stress-induced adrenocorticotropin release. Neuroendocrinology 50:433-446.

Hajnal A, Sandor P, Jando G, Vida I, Czurko A, Karadi Z, Lenard L (1992) Feeding disturbances and EEG activity changes after amygdaloid kainate lesions in the rat. Brain Res Bull 29:909-916.

Hawkins DM (1980) Identification of outliers. New York: Chapman and Hall.

Kalra SP, Dube MG, Sahu A, Phelps CP, Kalra PS (1991) Neuropeptide $Y$ secretion increases in the paraventricular nucleus in association with increased appetite for food. Proc Natl Acad Sci USA 88:10931-10935.

King BM, Kass JM, Neville KL, Sam H, Tatford III AC, Zansler CA (1993) Abnormal weight gain in rats with amygdaloid lesions. Physiol Behav 54:467-470.

King BM, Sam H, Arceneaux WR, Kass JM (1994) Effect on food intake and body weight of lesions in and adjacent to the posterodorsal amygdala in rats. Physiol Behav 55:963-966.

King BM, Cook JT, Dallman MF (1997) Hyperinsulinemia in rats with obesity-inducing amygdaloid lesions. Am J Physiol 271:R1156-R1159.

Kotz CM, Grace MK, Briggs JE, Levine AS, Billington CJ (1995) Effect of opioid antagonists naloxone and naltrexone on neuropeptide $\mathrm{Y}$-induced feeding and brown fat thermogenesis in the rat: neural site of action. J Clin Invest 96:163-170.

Lambert PD, Wilding JP, al-Dokhayel AA, Gilbey SG (1993) The effect of central blockade of kappa-opioid receptors on neuropeptide Y-induced feeding in the rat. Brain Res 629:146-148.

Lambert PD, Philips PJ, Wilding JPH, Bloom SR, Herbert J (1995) c-fos expression in the paraventricular nucleus of the hypothalamus following intracerebroventricular infusions of neuropeptide Y. Brain Res 670:59-65.

Levine AS, Morley JE (1984) Neuropeptide Y: a potent inducer of consummatory behavior in rats. Peptides 5:1025-1029.

Levine AS, Grace M, Billington CJ (1990a) The effect of centrally administered naloxone on deprivation and drug-induced feeding. Pharmacol Biochem Behav 36:409-412.

Levine AS, Grace M, Billington CJ, Portoghese PS (1990b) Norbinaltorphimine decreases deprivation and opioid-induced feeding. Brain Res 534:60-64.

Li B-H, Xu B, Rowland NE, Kalra SP (1994) c-fos expression in the rat brain following central administration of neuropeptide $\mathrm{Y}$ and effects of food consumption. Brain Res 665:277-284.

Minano FJ, Meneres Sancho MS, Sancibrian M, Salinas P, Myers RD (1992) $\mathrm{GABA}_{\mathrm{A}}$ receptors in the amygdala: role in feeding in fasted and satiated rats. Brain Res 586:104-110.

Morris BJ (1989) Neuronal localisation of neuropeptide Y gene expression in rat brain. J Comp Neurol 290:358-368.

Pages N, Orosco M, Rouch C, Yao O, Jacquot C, Bohoun C (1993) Refeeding after $72 \mathrm{hr}$ fasting alters neuropeptide $\mathrm{Y}$ and monoamines in various cerebral areas in the rat. Comp Biochem Physiol 106A:845-849.

Palkovits M, Mezey E, Skirboll LR, Hokfelt T (1992) Adrenergic projections from the lower brainstem to the hypothalamic paraventricular nucleus, the lateral hypothalamic area and the central nucleus of the amygdala. J Chem Neuroanat 5:407-415.

Paxinos G, Watson C (1986) The rat brain in stereotaxic coordinates. San Diego: Academic.

Petrov T, Krukoff TL, Jhamandas JH (1993) Branching projections of catecholaminergic brainstem neurons to the paraventricular hypothalamic nucleus and the central nucleus of the amygdala in the rat. Brain Res 609:81-92.

Petrov T, Krukoff TL, Jhamandas JH (1995) Convergent influence of the central nucleus of the amygdala and the paraventricular hypothalamic nucleus upon brainstem autonomic neurons as revealed by c-fos expression and anatomical tracing. J Neurosci Res 42:835-845.

Pickel VM, Van Bockstaele EJ, Chan J, Cestari DM (1995) Amygdala efferents form inhibitory-type synapses with a subpopulation of catecholaminergic neurons in the rat nucleus tractus solitarius. J Comp Neurol 362:510-523.

Rinaman L, Hoffman G, Dohanics J, Le W-W, Stricker E, Verbalis J (1995) Cholecystokinin activates catecholaminergic neurons in the caudal medulla that innervate the paraventricular nucleus of the hypothalamus in rats. J Comp Neurol 360:246-256.

Roder S, Ciriello J (1993) Innervation of the amygdaloid complex by catecholaminergic cell groups of the ventrolateral medulla. J Comp Neurol 332:105-122.

Sagar SM, Sharp FR, Curran T (1988) Expression of $c$-fos protein in brain: metabolic mapping at the cellular level. Science 240:1328-1331. 
Sahu A, Kalra PS, Kalra SP (1988) Food deprivation and ingestion induce reciprocal changes in neuropeptide $\mathrm{Y}$ concentrations in the paraventricular nucleus. Peptides 9:83-86.

Sawchenko PE, Swanson LW (1981) Central noradrenergic pathways for the integration of hypothalamic neuroendocrine and autonomic responses. Science 214:685-687.

Sawchenko PE, Swanson LW, Grzanna R, Howe PRC, Bloom SR, Polak JM (1985) Colocalization of neuropeptide Y immunoreactivity in brainstem catecholaminergic neurons that project to the paraventricular nucleus of the hypothalamus. J Comp Neurol 241:138-153.

Shibasaki T, Tsumori C, Hotta M, Imaki T, Demura H (1995) Intracerebroventricular administration of neuropeptide $\mathrm{Y}$ inhibits release of noradrenaline in the hypothalamic paraventricular nucleus caused by manual restraint in the rat through an opioid system. Brain Res 688:189-192.

Stanley BG, Leibowitz SF (1984) Neuropeptide Y: stimulation of feeding and drinking by injection into the paraventricular nucleus. Life Sci 35:2635-2642.

Stanley BG, Daniel D, Chin A, Leibowitz S (1985) Paraventricular nucleus injections of peptide YY and neuropeptide Y preferentially enhance carbohydrate ingestion. Peptides 6:1205-1211.

Stanley BG, Magdalin W, Seirafi A, Thomas WJ, Leibowitz SF (1993)
The perifornical area: the major focus of (a) patchily distributed hypothalamic neuropeptide Y-sensitive feeding system(s). Brain Res 604:304-317.

Verbalis JG, McCann MJ, McHale CM, Stricker EM (1986) Oxytocin secretion in response to cholecystokinin and food: differentiation of nausea from satiety. Science 232:1417-1419.

Warren WS, Adkison MG, Bartness TJ (1996) CNS neurons regulating the sympathetic outflow to white adipose tissue as revealed by transneuronal labeling with pseudorabies virus. Soc Neurosci Abstr 22:1412.

Watson Jr RE, Wiegand SJ, Clough RW, Hoffman GE (1986) Use of cryoprotectant to maintain long-term peptide immunoreactivity and tissue morphology. Peptides 7:155-159.

Xu B, Li B-H, Rowland NE, Kalra SP (1995) Neuropeptide Y injection into the fourth cerebroventricle stimulates cFos expression in the paraventricular nucleus and other nuclei in the forebrain: effect of food consumption. Brain Res 698:227-231.

Zardetto-Smith AM, Gray TS (1996) Catecholamine and NPY efferents from the ventrolateral medulla to the amygdala in the rat. Brain Res Bull 38:253-260.

Zittel TT, De Giorgio R, Sternini C, Raybould HE (1994) Fos protein expression in the nucleus of the solitary tract in response to intestinal nutrients in awake rats. Brain Res 663:266-270. 